\title{
The Preventive Use of Probiotics Against Gastrointestinal HAls in Ontario
}

\author{
Raphaella Bergeron Hartman ${ }^{1}$
}

${ }^{1}$ Trinity College School, Port Hope, ON L1A 4K7, Canada

\begin{abstract}
$\underline{\text { ABSTRACT }}$
Given confounding evidence in the literature and the lack of standardized guidelines in Canada, little is known about the process through which clinical dieticians decide whether or not to implement a probiotics course with the intent of preventing gastrointestinal healthcare-associated infections (HAIs) in Ontario. This study uses a mixed-method design featuring a content analysis of the literature and a survey addressed to clinical dietitians in Ontario to investigate (a) the likelihood of clinical dietitians in recommending probiotics course to prevent gastrointestinal healthcare-associated infections (HAIs) and (b) their reasoning in setting certain parameters of such a probiotics course. Among the four respondents obtained for the survey, all ranked their likelihood of prescribing probiotics to prevent nosocomial gastrointestinal infections as medium or less. The determination of parameters in a course were largely influenced by guidelines and/or evidence, case-specific consideration and fixed procedures, as these were mentioned among other themes by the largest number of respondents and were included in the largest amount of questions on average. Finally, parameters which the majority of respondents determined using the same themes were the dose of probiotics, timing of the course with regards to antibiotics, and type of probiotics.
\end{abstract}

\section{Introduction}

According to the World Health Institute, healthcare-associated infections (HAIs) are the most common adverse side effect resulting from health care delivery (2014), killing about 8,000 Canadians and infecting 220,000 others each year (CPSI, 2010). Also called nosocomial diseases, these consist of "infectious diseases typically acquired in health care facilities such as hospitals," as defined by Public Health Ontario.

Along with their spread in hospital settings - thus impacting already weakened patients - HAIs represent a considerable challenge to health care delivery due to the ability of some of these pathogens to resist drugs and/or antibiotics. As a result, current policies, often focusing on damage control, are left struggling (Pettigrew et al, 2016). Among prospective solutions, a prominent lead is to leverage the gut flora ${ }^{1}$ using probiotics. ${ }^{2}$ The aim behind this is to enhance the patient's immune system and provide colonization resistance at the bacterial level. In Ontario, although it is not unusual for dietitians in hospitals to recommend courses of probiotics to inpatients, there remains no standardized guidelines to regulate the administration of probiotics. The main reason for this is that the current body of research does not display a clear consensus concerning (a) whether or not probiotics are efficient in preventing HAIs and (b) how to determine different parameters concerning a course of probiotics (eg. strains of microorganisms, duration, timing, frequency, and dose). This leads one to question the extent to which the differing recommendations available in the literature are translatable to the practice of dietitians in hospitals. In light of this, the proposed question is "Given the lack of standardized guidelines, how likely are clinical dieticians in Ontario to recommend probiotics to

${ }^{1}$ The gut flora comprises the community of microorganisms naturally inhabiting the human digestive tract (e.g. bacteria, fungi, viruses) and interacting with the body through the intestinal membrane

${ }^{2}$ Dietary intake of beneficial live microorganism 
inpatients in order to prevent gastrointestinal healthcare-associated infections following a course of antibiotics, and what rationales do they consider when determining the parameters of such a probiotics course?"

\section{Literature Review}

\section{Cause and Effect: Antibiotics and the Recent Prevalence of HAIs}

In recent years, the use of antibiotics has become a double-edged sword: on one hand, saving countless lives, yet on the other, catalysing the emergence of antimicrobial resistance. The latter has been of increasing concern to health care systems given its prevalent emergence in a number of pathogens; coincidingly, treatments to address these leads to poor success rates, as the standard approach is often antibiotics. This sets the scene for a vicious cycle, given that using more aggressive antibiotics to fight off resistant pathogens often leads said pathogens to become more resistant still. This effect also leads to an increased prevalence of infection in hospitals, including recurrence, which can be attributed in part to the widespread use of antibiotics in in-patients.

Thus, infections transmitted in hospital settings, referred to as "nosocomial" or "healthcare-associated infections" (HAIs), tend to prey on patients having undergone a course of antibiotics. For such individuals, antibiotics tend to weaken a key player in the body's natural defense system: the gut flora. Maintaining balance in the gut flora is essential, as, putting its many benefits aside, it often contains opportunistic pathogens. While these remain contained in a balanced gut flora, if a disbalance is induced, whereby antibiotics lessen numbers of beneficial microorganisms, opportunistic pathogens have the chance to expand and cause infection - hence their "opportunistic" designation (Shannon-Lowe et al, 2010). For this reason, a healthy individual may have a positive stool sample for a widespread gastrointestinal nosocomial pathogen like Clostridium-Difficile (C-Difficile), even a resistant strain, without being infected. This, in a hospital setting, increases the risk of infection of more vulnerable patients, namely those undergoing an antibiotics course.

\section{Why Probiotics?}

An article published in the journal Clinical Infectious Diseases outlines the following premise: "Because major disturbances in the intestinal flora occur before and coincident with the development of CDAD [Clostridium-Difficile associated diarrhea], the reestablishment of normal fecal flora makes sense as a means of controlling this disease" (Miller, 2007) The same logic is behind the clinical use of fecal matter transplants in recent years for patients having experienced recurrence of a nosocomial gastrointestinal infection. When looking at prevention, however, the equivalent would be achieved through the administration of probiotics. The aim with this approach would be to prevent "major disturbances in the intestinal gut flora," thus maintaining rather than reestablishing the normal gut flora. Additionally, the mutualistic ${ }^{3}$ relationship between the gut flora and the body enhances enteric ${ }^{4}$ and systemic ${ }^{5}$ immunity, implying that the benefits of a healthy gut flora thus reach far beyond intestinal health (Haak et al, 2018). As such, recommending a course of probiotics is a common approach for preventing gastrointestinal HAIs, especially alongside a course of antibiotics.

${ }^{3}$ In biology, a relationship between two or more organisms from which both parties are benefiting

${ }^{4}$ Immunity relative to intestinal infection

${ }^{5}$ Immunity relative to sepsis (ie. full body infection) 


\section{Probiotics in Clinical Practice: Trends in the Literature}

Worrisome reports of antimicrobial resistance in HAIs appear in the literature as of the early 2000's, following which alternative approaches such as probiotics were investigated. Still, due to a constantly evolving understanding of the variables coming into play, dissensus pertaining to the role of probiotics persists to this day.

For instance, while a main claim is that the beneficial outcomes of probiotics observed in various studies are not reproducible, some answer this by pointing out various confounding variables. For example, Szajewska (2010) cautions against overinterpretations of meta-analyses which do not differentiate between probiotic strains, due to the effects of probiotics being strain specific. In fact, each individual's gut flora composition is unique, meaning that the impact of a specific type of probiotic cannot be generalized for all individuals. As well, an earlier study points out the difficulty behind mathematical modeling of the results of probiotics administration in studies with few participants (Starr, 2005) agreeing with a more recent article encouraging longer follow up periods in future studies (Clarkin et al, 2009). The fact that these factors, among others, are often overlooked in the literature, namely due to study-specific limitations, leads some to question the quality of evidence presented.

For instance, a report by the McGill University Health Center (2005) did not recommend the use of probiotics alongside an antibiotics course for the prevention of C-Difficile infection on the basis that evidence was still inadequate. Later on, a systematic review of meta-analyses mandated by the government of Quebec (Levesque et al, 2017) similarly concluded that the quality of evidence was insufficient towards establishing a standardized guideline for the clinical administration of probiotics, although recognizing their potential.

Meanwhile, the recommendation of probiotics alongside an antibiotics course is not unusual, nonetheless. In fact, a cost-effectiveness analysis reviewing the literature found that on average inpatients taking probiotics were at a lower risk of C-Difficile ( $2 \%$ vs 5.5\%) and had a lower overall cost of stay (CDN \$327 vs \$845) (Leal et al, 2016). The following year, a meta-analysis comprising solely of randomized and controlled trial studies, amounting to 39 studies and 9955 participants, found that inpatients taking probiotics were $60 \%$ less likely to develop CDAD, while yet rating their results as "moderate certainty evidence" (Goldenberg et al, 2017).

\section{Gap: Common Practice in Ontario}

As the literature entertains a certain amount of uncertainty, one can only imagine that credence in the effectiveness of probiotics can vary from one professional to the other, potentially influencing their likelihood to recommend a course. With this in mind, a question regarding the uniformity within clinical practice arises, especially given the lack of standardized guidelines in Canada, including in the province of Ontario.

In fact, at the moment, probiotics are regulated as dietary supplements, not medicine. As a result, their distribution, as long as the products are Generally Recognized As Safe (GRAS), undergoes little restrictions (Loo, 2018). Meanwhile, even the identification of gastrointestinal HAIs, such as Clostridium-Difficile (C-Difficile), is mitigated, as reported by a study surveying healthcare professionals on the front lines of HAI identification (Keller et al, 2013). A similar design to that study is suggested here; however, this investigation is directed specifically at the practices of clinical dietitians in Ontario, who hold a central role in the recommendation of probiotics in hospitals. The aim of the present investigation is to (a) evaluate the likelihood of clinical dietitians in recommending probiotics to prevent gastrointestinal HAIs and (b) the factors that they consider in designing a probiotics course. To this end, the proposed research question is "Given the lack of standardized guidelines, how likely are clinical dieticians in Ontario to recommend probiotics to inpatients in order to prevent gastrointestinal healthcare-associated infections following a course of antibiotics, and what rationales do they consider when determining the parameters of such a probiotics course?" 


\section{Hypotheses}

Given the lack of official guidelines, both provincial and national, as well as the mitigated reports on the benefits of probiotics in the literature, I hypothesized that rationales in determining parameters of a probiotics course would vary widely from one dietitian to another. As well, I assumed that the likelihood of clinical dietitians to recommend probiotics to inpatients would be moderate, consistently with the moderate consensus in the literature on the extent of the benefits of probiotics.

\section{Methods}

The present investigation was designed as a non-experimental, mixed-method study. Data collection was executed using a content analysis of the existing literature, which laid the groundwork for a survey addressed to clinical dietitians in Ontario. Moreover, while both means of data collection were interpreted using a qualitative analysis, the latter also included a quantitative analysis.

\section{Content Analysis}

The content analysis was an essential prerequisite for the survey. In fact, the second part of the survey focused on parameters of a probiotics course, as clinical dietitians have to determine these in real life emitting recommendations. By asking for their reasoning in setting a variety of parameters, the aim was to see a representative range of themes emerge from their reasoning. It must be noted that the focus of this investigation was not to establish a correlation between specific parameters and rationales, but rather to see, all parameters confounded, which themes would emerge among rationales.

Nevertheless, such parameters were not easily identifiable, as different sources tended to specify different parameters. The content analysis of the literature thus served the purpose of identifying the most common parameters from credible sources, selected as follows.

Firstly, Google Scholar was searched with the term "probiotics guidelines" in combination with the following:

- Clostridium-Difficile

- HAIs

- Hospital

- Nosocomial infections

- Gastrointestinal infections

Secondly, while the search terms were directed at guidelines, studies and reviews were also accepted if these included recommendations for probiotics. Some search results were also discarded on the basis of their relevance, leaving me with 15 sources. Finally, these were organized chronologically in a table (Appendix C, Table 11) which specified methods, authors, journals, dates of publication, summarized key findings and identified the specified parameters.

\section{Survey}

Following the content analysis, which provided an essential understanding of the topic, a survey was crafted to investigate the process through which clinical dietitians in Ontario determine a course of probiotics. Questions were then separated in two sections.

The first section included one question pertaining to the confidence of clinical dietitians in the effectiveness of probiotics and one pertaining to their likelihood in recommending a course of probiotics. These were used to get a 
sense of whether or not the dissensus in the literature was transposable to clinical dietitians in Ontario. A quantitative analysis was chosen to compute in a comparable fashion the confidence of dietitians in the effectiveness of probiotics and the likelihood in recommending a course. This was performed using Likert Scales, which provide numerical values ( 1 to 5) to which respondents can identify their beliefs and behaviours. Results were conveyed in the form of percentages using a scientific calculator.

The second section inquired about the rationales the respondents used to determine specific parameters when recommending a probiotics course. The chosen parameters were identified through the aforementioned content analysis. A qualitative analysis was required given the use of open-ended questions. Open-ended questions served the purpose of following up on the Likert scale questions and providing an insight on how dietitians decide to determine a probiotics course with respect to specific parameters. These were essential to get a comprehensive view on the present topic of inquiry as I could not predict with certainty the reasoning behind the clinical dietitians' responses. Moreover, responses were coded according to themes. Following the model of a deductive approach, these were chosen based on identifiable categories within the responses. I then used percentages, calculated using a scientific calculator, to identify (a) the variations in responses for each parameter, (b) the number of questions for which each theme was used on average and (c) the percentage of respondents which identified each theme at least once.

\section{Participants}

Participants consisted of registered dietitians working in hospitals (ie. clinical dietitians) in light of their central role in the recommendation of probiotics to in-patients. These were found through non-random selection types, starting with purposive sampling. I first contacted dietitians from my network through word of mouth, asking them to send my survey to clinical dietitians practicing in Ontario. Additionally, I attempted to contact clinical dietitians through the Dietitians of Canada association website. Using the search settings of the website, I found a multitude of dietitians practicing in Ontario and having clinical experience but only four currently practicing. Using the available contact information, I sent them an email (Appendix A) detailing the purpose of my study and asking them to respond to my survey but got no response. As well, one of the dietitians mentioned above posted the survey to their "Dietitian's Support Group" Facebook page, extending my sampling method to voluntary response sampling.

\section{Final Touches and Approval}

To ensure the eligibility of respondents (ie. that they were clinical dietitians and practicing in Ontario), preliminary questions were included (Appendix B, Tables 1 and 2). The anonymity of respondents was maintained as no identification was required, and I adjusted the settings of the Google form to not collect the respondents' email addresses. The survey was proofread by two dietitians (Andrea Miller MHSc, RD and Kerry Grady MHSc, RD) before distribution to ensure that the correct terminology was used and a trial was sent out to a clinical dietitian that they connected me with. This enabled me to clarify questions 7 to 13. Finally, before distribution, my school's Institutional Review Board approved the study from an ethical standpoint, given the involvement of human participants.

\section{Results}

\section{Content Analysis}

Main parameters of a probiotics course were identified by grouping features of probiotics courses specified in studies or recommended in articles (Appendix C, Table 11). The resulting parameters were timing, duration, frequency, dose and type. 


\section{Timing}

Timing is viewed with regards to an antibiotics course (ie. before, during, after) given the impact of antibiotics on the gut flora. This agrees with recent studies (Shen et al, 2017; Moore 2018) which found different efficacy of probiotics courses depending on how close the start of the course of probiotics was to that of the antibiotics course. In fact, as probiotics aim to compensate for an antibiotics-induced disruption of the gut flora, different timings may have different reparatory effects, depending on the extent of damage already present at one point in time.

\section{Duration}

The duration of a probiotics course was specified in reviews by Zuccotti \& Meneghin (2014) and Wilkins \& Sequoia (2017) as well as in a study reported by Moore (2018). This parameter should be determined considering the targeted disease and type of probiotics used as these will affect the interaction between the probiotic and the gut flora, including the amount of time required for its benefits to be noticeable (Wilkins \& Sequoia 2017).

\section{Frequency}

Frequency of probiotics intake is mentioned in the methods of a study by Rojas et al (2012). This is essential as microorganisms that are not indigenous to the host may not stay in the gut long enough for their impact to be substantial. For instance, if an individual takes a probiotic only once, the "new" microorganisms will be flushed out within a certain amount of time. The frequency of probiotic uptake thus contributes to ensuring that their effect is maintained.

\section{Dose}

Mention of the dose of probiotics, often stated in terms of CFU, was found in the methods of a study (Rojas et al, 2012) and reviews commented on how it impacted efficacy of a course (Zuccotti \& Meneghin, 2014; Shen et al, 2017; Wilkins \& Sequoia, 2017; Guarner et al, 2017; Sniffen et al, 2018). This is essential as an insufficient dose may not reach maximal benefits of a probiotics course. In fact, if not enough of the probiotic microorganisms are present with respect to the numbers of microorganisms already present, their effect might go unnoticed.

\section{Type}

The type of probiotics encompassed phylogenetic specifications of probiotics, probiotic combinations (ie. multi-probiotics or single species) and formulation/mode of administration. Phylogenetic terms included genus (Garner et al, 2017), species (Garner et al, 2017; Wilkins \& Sequoia 2017; Moore, 2018), and strain (Dendukuri et al, 2005; Ciorba, 2012; Zuccotti \& Meneghin 2014; Garner et al 2017; McDonald et al, 2017; Sniffen et al, 2018). Differentiation among genus/species/strain of probiotics is essential as their interaction with the gut flora and pathogens responsible for HAIs has been shown to vary in accordance. Accordingly, combined probiotics products versus single species probiotics products have different effects (Verna \& Lucak, 2010; Moore, 2018). Moreover, formulation can include namely food or pills (Sniffen et al, 2018), and should be selected depending on the patient (eg. the Rojas et al. study (2012) on the benefits of probiotics in preterm babies uses drops as these are best suited for newborns).

\section{Survey}

\section{Eligibility}

Although there were 5 respondents, one was rejected (Respondent \#3) as they were not a clinical dietitian, nor practicing in Ontario (Appendix B, Tables 1 and 2).

\section{Section 1: Likelihood and Confidence in Prescription of Probiotics}

Question \#3 addressed the likelihood of respondents to recommend probiotics alongside a course of antibiotics to lessen vulnerability to gastrointestinal HAIs. Ranking their opinion on a Likert Scale (1 being very unlikely; 5 being 
very likely), two respondents (50\%) answered 2, while the remaining two (50\%) answered 3 (Table 3). While results were adjacent suggesting similar opinions, each respondent resorted to different explanations (Table 4).

Table 3. Responses to Question \#3, "As a dietitian, how likely are you to recommend a course of probiotics to inpatients alongside an antibiotic course?"

\begin{tabular}{|c|c|c|c|c|c|c|c|}
\hline Likert & 1-very unlikely & \multicolumn{2}{|c|}{2} & \multicolumn{2}{|c|}{3} & 4 & 5 - very likely \\
\hline Responses & $0(0 \%)$ & \multicolumn{2}{|c|}{$2(50 \%)$} & \multicolumn{2}{|c|}{$2(50 \%)$} & $0(0 \%)$ & $0(0 \%)$ \\
\hline Respondents & $\mathrm{N} / \mathrm{A}$ & 2 & 4 & 1 & 5 & $\mathrm{~N} / \mathrm{A}$ & $\mathrm{N} / \mathrm{A}$ \\
\hline
\end{tabular}

Table 4. Thematic Analysis of Question \#4, "Please explain your reasoning to your answer to \#3"

\begin{tabular}{|l|c|c|l|}
\hline \multicolumn{1}{|c|}{ Rationale } & $\begin{array}{c}\text { Amount of } \\
\text { responses }\end{array}$ & Respondent & Answer \\
\hline Not enough evidence & $1(25 \%)$ & 1 & "Not enough evidence" \\
\hline Refer to guidelines/evidence & $1(25 \%)$ & 4 & $\begin{array}{l}\text { "I follow general evidence provided via probiotic- } \\
\text { chart.ca" }\end{array}$ \\
\hline Specific to the case & $1(25 \%)$ & 5 & $\begin{array}{l}\text { "It depends on how long of a course of antibiotics } \\
\text { the patient is on. If only a few days, I won't suggest } \\
\text { a probiotic. However if they are on antibiotics for a } \\
\text { few weeks, I will." }\end{array}$ \\
\hline Fixed procedure & $1(25 \%)$ & 2 & $\begin{array}{l}\text { "Well i'd [sic] recommend it after the [antibiotics] } \\
\text { course is finished" }\end{array}$ \\
\hline Unsure & $0(0 \%)$ & N/A & N/A \\
\hline
\end{tabular}

Question \#5 addressed the confidence of the respondents in the ability of probiotics to prevent gastrointestinal HAIs. Ranking their belief on a Likert Scale ( 1 being very ineffective; 5 being very effective), one respondent (25\%) answered 2, two respondents (50\%) answered 3, and one respondent (25\%) answered 4 (Table 5). While a slightly lesser proximity of responses is observed here than that of Question \#3, participants having answered differently could explain themselves using the same rationales. For instance, while both respondents 1 and 2 referred to the theme of "Evidence," they respectively answered 4 and 2, which are relatively distant on the Likert Scale (Table 6). On the other hand, the explanations of respondents having answered 3 were either classified as "Unsure" or "Specific to the case." 
Table 5. Responses to Question \#5, "To your knowledge, how beneficial are probiotics in preventing infections caused by multidrug-resistant and/or antibiotic-resistant organisms, such as C-Difficile, in inpatients going through/ having gone through an antibiotic course?"

\begin{tabular}{|c|c|c|c|c|c|c|}
\hline Likert & 1-very ineffective & 2 & \multicolumn{2}{|c|}{3} & 4 & 5 - very effective \\
\hline Responses & $0(0 \%)$ & $1(25 \%)$ & \multicolumn{2}{|c|}{$2(50 \%)$} & $1(25 \%)$ & $0(0 \%)$ \\
\hline Respondents & N/A & 2 & 4 & 5 & 1 & N/A \\
\hline
\end{tabular}

Table 6. Thematic analysis of responses to Question \#6, "Please explain your reasoning to Question \#5"

\begin{tabular}{|c|c|c|c|}
\hline Rationales & $\begin{array}{l}\text { Amount of } \\
\text { responses }\end{array}$ & Respondent & Answer \\
\hline Not enough evidence & $0(0 \%)$ & N/A & N/A \\
\hline \multirow{2}{*}{$\begin{array}{l}\text { Refer to guidelines/ } \\
\text { evidence }\end{array}$} & \multirow[t]{2}{*}{$2(50 \%)$} & 1 & "based on evidence" \\
\hline & & 2 & $\begin{array}{l}\text { "the little evidence that there is shows strong promise in } \\
\text { preventing these infections" }\end{array}$ \\
\hline Specific to consult & $1(25 \%)$ & 5 & $\begin{array}{l}\text { "Research in this area is soft; and again, it depends on how } \\
\text { long the patient is on antibiotics - one course will not nec- } \\
\text { essarily put them at risk." }\end{array}$ \\
\hline Fixed procedure & $0(0 \%)$ & N/A & N/A \\
\hline Unsure & $1(25 \%)$ & 4 & "Not my expertise- totally unsure" \\
\hline
\end{tabular}

\section{Section 2: Rationales Involved in the Determination of a Probiotics Course}

Questions \#7 through \#12 (Appendix B) aimed to identify the various rationales of clinical dietitians in setting the parameters of a probiotics course, selected previously in the content analysis. To this end, the baseline question ("As a dietitian, what factors/cues enable you to decide...") was featured as a heading, and each following question addressed a specific parameter, completing the sentence (Table 8). The rationales identified through a thematic analysis of responses were the cost of probiotics, patient compliance, considerations specific to the consulting case, referral to guidelines and/or evidence, the use of fixed procedures, and uncertainty (Table 7). 
Table 7. Definition of Themes Obtained from the Thematic Analysis of Questions \#7 to \#12.

\begin{tabular}{|c|c|}
\hline \multirow{2}{*}{ Rationales } & Definition \\
\hline & The determination of a parameter of the course is influenced by... \\
\hline Cost & ...the cost of probiotics \\
\hline Patient Compliance & ...patient willingness to follow the probiotics course \\
\hline \multirow[t]{2}{*}{ Specific to Consult } & $\begin{array}{l}\text {... a characteristic of the consulting patient's case, such as patient predisposition/ contrain- } \\
\text { dications }\end{array}$ \\
\hline & Ex: "IV continuous VS PO antibiotics" (see Appendix B, Table 6.1, Respondent \#1) \\
\hline \multirow[t]{2}{*}{ Guidelines/ Evidence } & $\ldots$ the referral of the respondent to published works \\
\hline & $\begin{array}{l}\text { Ex: "Based on evidence as per reason for use from examine.com" (see Appendix B, Table } \\
6.5 \text {, Respondent \#2) }\end{array}$ \\
\hline \multirow[t]{2}{*}{ Fixed procedure } & (no indication that the recommendation could vary depending on external factors) \\
\hline & Ex: "We use BioK 1 tablet daily" (see Appendix B, Table 6.4, Respondent \#5) \\
\hline Unsure & (the respondent expresses uncertainty towards setting a parameter) \\
\hline
\end{tabular}

Table 8. Thematic Analysis of Answers to Questions \#7 to \#12 Inquiring on the Determination of Parameters of a Probiotics Course.

\begin{tabular}{|c|c|c|c|c|c|c|}
\hline \multirow{3}{*}{ Parameters } & \multicolumn{6}{|c|}{ Themes } \\
\hline & Cost & $\begin{array}{c}\text { Patient } \\
\text { com- } \\
\text { pliance }\end{array}$ & $\begin{array}{l}\text { Specific } \\
\text { to consult }\end{array}$ & $\begin{array}{l}\text { Guidelines/ } \\
\text { evidence }\end{array}$ & $\begin{array}{l}\text { Fixed proce- } \\
\text { dure }\end{array}$ & Unsure \\
\hline & \multicolumn{6}{|c|}{ "As a dietitian, what factors/cues enable you to decide..." } \\
\hline $\begin{array}{l}\ldots \text { the timing of a probiotics course } \\
\text { with respect to an antibiotics course? }\end{array}$ & I & & III & & & \\
\hline ... the duration of a probiotics course? & I & & I & I & I & I \\
\hline $\begin{array}{l}\text {... the frequency of consumption of } \\
\text { probiotics? }\end{array}$ & & I & & I & II & \\
\hline ... the dose of probiotics? & & & & III & I & \\
\hline ...the type of probiotics? & & & II & III & I & \\
\hline
\end{tabular}


One takeaway is that the timing, type, and dose of probiotics were the parameters which respondents determined the most similarly: In each of these, three respondents out of four (75\%) answered using the same themes (Table 8). On the other hand, fewer similar responses were obtained in questions pertaining to the frequency (two) and duration of a probiotics course (none). This shows that the consistency in the rationales identified by respondents is not the same throughout and varies according to the parameter.

The themes included on average in the largest number of parameters were "Evidence/guidelines," "Specific to consult," and "Fixed procedure," respectively with means of 2, 1.5 and 1.25 responses per respondent (40\%, 30\% and 25\%) (Table 9). (In other words, the average participants would mention "Evidence/guidelines" in determining two parameters out of five). This suggests that these three themes are relevant in setting a larger amount of parameters. As well, these themes were mentioned at least once by half or more of the respondents (respectively 3 (75\%), 4 (100\%) and $2(50 \%)$ ) (Table 10). This shows that, regardless of the amount of parameters to which these themes apply, half or more of the respondents were at least aware of said themes, contributing to establishing these as a core component of the respondents' reasoning. On a side note, interestingly enough, two of the six responses coded as "Specific to consult" explained that aspects of the antibiotics course would be taken into consideration (Appendix B, Table 6.1, Respondents 1 and 5).

Meanwhile, the themes used on average in determining the least amount of parameters were "Cost," "Unsure," and "Patient compliance." The prior had a mean of 0.5 responses per respondent (10\%) and the two latter, 0.25 $(5 \%)$ (Table 9), which suggests that these do not apply to a majority of parameters. On the other hand, while "Patient compliance" and "Unsure" were both only included by one respondent (25\%), "Cost" was mentioned at least once by two respondents $(50 \%)$ (Table 10). This means that half of respondents are aware of this in determining a probiotics course, which is as much as for "Fixed Procedure." Interestingly enough, one of the two responses referring to this theme read as "cost to client," meaning that this could consist of a limitation.

Table 9. Mean Number of Questions in which Respondents Identified Each Theme.

\begin{tabular}{|c|c|c|c|c|c|c|}
\hline \multirow[b]{2}{*}{ Respondent } & \multicolumn{6}{|c|}{ Themes } \\
\hline & Cost & $\begin{array}{l}\text { Patient com- } \\
\text { pliance }\end{array}$ & $\begin{array}{l}\text { Specific to } \\
\text { consult }\end{array}$ & $\begin{array}{l}\text { Guidelines/ } \\
\text { evidence }\end{array}$ & $\begin{array}{l}\text { Fixed pro- } \\
\text { cedure }\end{array}$ & Unsure \\
\hline 1 & $1(20 \%)$ & $1(20 \%)$ & $2(40 \%)$ & $4(80 \%)$ & & \\
\hline 2 & $1(20 \%)$ & & $1(20 \%)$ & $2(40 \%)$ & $2(40 \%)$ & \\
\hline 4 & & & $1(20 \%)$ & $2(40 \%)$ & & $1(20 \%)$ \\
\hline 5 & & & $2(40 \%)$ & & $3(60 \%)$ & \\
\hline $\begin{array}{c}\text { Mean number of questions } \\
\text { per respondent }\end{array}$ & $\begin{array}{c}0.5 \\
(10 \%)\end{array}$ & $0.25(5 \%)$ & $1.5(30 \%)$ & $2(40 \%)$ & $1.25(25 \%)$ & $\begin{array}{l}0.25 \\
(5 \%)\end{array}$ \\
\hline
\end{tabular}


Table 10. Amount of Times Each Theme Was Identified by Respondents.

\begin{tabular}{|c|c|c|c|c|c|c|}
\hline \multirow{2}{*}{ Respondent \# } & \multicolumn{5}{|c|}{ Themes } \\
\cline { 2 - 7 } & Cost & $\begin{array}{c}\text { Patient } \\
\text { compliance }\end{array}$ & $\begin{array}{c}\text { Specific } \\
\text { to consult }\end{array}$ & $\begin{array}{c}\text { Guidelines/ } \\
\text { evidence }\end{array}$ & $\begin{array}{c}\text { Fixed pro- } \\
\text { cedure }\end{array}$ & Unsure \\
\hline 1 & I & I & II & IIII & & \\
\hline 2 & I & & I & II & II & \\
\hline 4 & & & I & II & & I \\
\hline 5 & & & II & & III & \\
\hline $\begin{array}{c}\text { Number of respondents having } \\
\text { identified each theme at least } \\
\text { once }\end{array}$ & $2(50 \%)$ & $1(25 \%)$ & $4(100 \%)$ & $3(75 \%)$ & $2(50 \%)$ & $1(25 \%)$ \\
\hline
\end{tabular}

\section{Discussion}

Firstly, the likelihood of recommendation of probiotics by clinical dietitians was moderate or less. This matches the moderate consensus on the benefits of probiotics in published works, agreeing with the hypothesis. Moderate or below moderate confidence in the benefits of probiotics, expressed by $75 \%$ of respondents, offers a hint as to how the effects of the opinion of probiotics portrayed in the literature affects the likelihood of clinical dietitians to recommend probiotics. As such, extending the clinical applications of probiotics in the future would require a firmer consensus in the literature, thus potentially improving the confidence of dietitians in the effectiveness of probiotics, and subsequently increasing their likelihood of prescription.

Secondly, themes among the rationales of clinical dietitians in setting parameters of a probiotics course were (1) specific to the consulting case, (2) following fixed procedures, (3) referencing guidelines and/or evidence, (4) concerning the cost of probiotics, (5) concerning patient compliance, (6) or uncertain. The present study identified the first three themes as most prominent given that these served, on average, to justify the most parameters, and were mentioned by more than half of respondents (respectively 100\%, 75\%, and 50\%) for at least one parameter. Moreover, the hypothesis according to which rationales behind the determination of certain parameters would vary widely among clinical dietitians, given the lack of consensus in the literature, is challenged however as some parameters (timing, dose and type) obtained more consensus than others (duration and frequency). Possible causes, while not having been examined in this study, could lie in the amount of published works specifying each parameter; thus, clinical dietitians might rely on more similar justifications when determining a parameter widely discussed in the literature, versus not.

Furthermore, while considerations specific to the case agree with the premise in the literature that the effects of probiotics are case specific, some dietitians still seemed to follow fixed procedures. This contradiction could be due to varying levels of confidence in the efficiency of probiotics: a dietitian could perhaps think that probiotics are useful, but that current knowledge is not extensive enough that subtle differences in a given parameter of a course would cause substantial change. Nonetheless, the referral to guidelines and evidence shows that dietitians do in fact consult published works, although none to date are official. While some believe that establishing an official guideline is premature given the persisting uncertainties on how to best prescribe probiotics, this will likely be useful in the 
future to prevent professionals from consulting contradictory references. The content analysis in this study offers suggestions as to which parameters should be clarified in such a guideline.

Finally, interesting mentions in responses included the referral to the antibiotics in rationales to determine a probiotics course. This suggests that, regardless of the lack of official guidelines, the literature (eg. Shen et al., 2017, see Appendix C) and some clinical dietitians agree that the impact of probiotics is linked to antibiotics and that a course of probiotics should be adjusted in accordance. Further research should also investigate the concern of the cost of probiotics, as one response seemed to imply that this was a limitation, while some published works argue that probiotics diminish costs in the long run (Leal et al, 2016).

\section{Limitations}

The central use of thematic analyses in this study implies a risk of overinterpretation of responses. For instance, the theme "Fixed procedure" was identified from the data on the basis that the respondent named a procedure, without specification that it could vary. As this does not rule out the possibility that such a procedure could vary, I made an educated assumption by coding data as such.

Likewise, the subjectivity Likert Scales coupled with the small sample of respondents makes extrapolation from the thematic analysis of questions following up Likert Scales inadequate, which is why these are not brought up in the discussion. In fact, given that Likert Scales are subjective, commenting on the similarity of follow up responses of respondents having selected the same answer on the Likert Scale would not have been meaningful. Perhaps this limitation could have been compensated for had the survey obtained a larger number of respondents, as error due to subjectivity would presumably be overcome.

Finally, the small sample of respondents (only four eligible) caused results to be poorly transposable to the larger body of clinical dietitians in Ontario. The findings suggested in this study thus propose areas which future, larger-scale studies should corroborate.

\section{References}

Agamennone, V., Krul, C. A. M., Rijkers, G., \& Kort, R. (2018). A practical guide for probiotics applied to the case of antibiotic-associated diarrhea in the Netherlands. BMC Gastroenterology, 18(103).

https://doi.org/10.1186/s12876-018-0831-x

Ciorba, M. A. (2012). A gastroenterologist's guide to probiotics. Clinical Gastroenterology \& Hepatology, 10(9). https://doi.org/10.1016/j.cgh.2012.03.024

Clarkin, C., Quist, S., Shamis, R., King, A. E., \& Shah, B. (2019). Management of Clostridioides Difficile infection. Critical Care Nurse, 39(5). https://doi.org/10.4037/ccn2019841

CPSI. (n.d.). Healthcare-associated infections [Fact sheet]. Retrieved May 12, 2020, from https://www.patientsafetyinstitute.ca/Pages/PageNotFoundError.aspx?requestUrl=https://www.patientsafetyinstitute.ca/en/About/Programs/HH/Documents/Fact\%20Sheets/Fact\%20Sheet $\% 201 \% 20$ The \%20Need\%20for\%20Better\%20Hand\%20Hygie ne.pdf

Dendukuri, N., Costa, V., \& McGregor, M. (n.d.). The use of probiotics in the prevention and treatment of Clostridium Difficile diarrhea (Report No. 18). 
Garner, F., Sanders, M. E., Eliakim, R., Fedorack, R., Gangl, A., Garisch, J., . . Le Mair, A. (2017, February). World Gastroenterology Organization Global Guidelines: Probiotics and prebiotics. Retrieved from https://www.worldgastroenterology.org/guidelines/global-guidelines/probiotics-and-prebiotics/probiotics-and-prebiotics-english

Goldenberg, J. Z., Yap, C., Lytvyn, L., Ka-Fung, C., Beardsley, J., Mertz, D., \& Johnson, B. (2017). Probiotics for the prevention of Clostridium difficile-associated diarrhea in adults and children. Cochrane Database System Review, 2017(2). https://doi.org/10.1002/14651858.CD006095.pub4

Government of Quebec Institut National d'Excellence en Santé et en Services Sociaux. (2017). Efficacité et innocuité des probiotiques en prévention des diarrhées associées à Clostridium difficile : revue systématique avec métaanalyses (A. Lévesque, J. Daigle, \& M. Tardif, Authors). Retrieved from http://numerique.banq.qc.ca/patrimoine/details/52327/2960091?docref=pt7jip-DOPxqw3qWSL8mfQ\&docsearchtext=Probiotics

Haak, B. W., Prescot, H. C., \& Wiersinga, W. J. (2018). Therapeutic potential of the gut microbiota in the prevention and treatment of sepsis. Frontiers in Immunology, 9(2042). https://doi.org/10.3389/fimmu.2018.02042

Keller, S. C., Linkin, D. R., Fishman, N. O., \& Lautenbach, E. (2013). Variations in identification of healthcare-associated infections. Infection Control and Hospital Epidemiology, 34(7). https://doi.org/10.1086/670999

Leal, J. R., Heitman, S., Conly, J., \& Henderson, E. (2016). Cost-effectiveness analysis of the use of probiotics for the prevention of Clostridium difficile-Associated diarrhea in a provincial healthcare system. Infection Control and Hospital Epidemiology, 37(9). https://doi.org/10.1017/ice.2016.134

Loo, V., Davis, I., Embil, J., Evans, G. A., Hota, S., Lee, C., . . Valiquette, L. (2018). Association of Medical Microbiology and Infectious Disease Canada treatment practice guidelines for Clostridium difficile infection. Official Journal of the Association of Medical Microbiology and Infectious Disease Canada, 3(2).

https://doi.org/10.3138/jammi.2018.02.13

McDonald, L. C., Gerding, D. N., Johnson, S., Bakken, J. S., Carroll, K. C., Collin, S. E., . . Wilcox, M. H. (2018). Clinical practice guidelines for Clostridium Difficile infection in adults and children: 2017 update by the infectious Diseases Society of America (IDSA) and society for healthcare epidemiology of America (SHEA). Clinical Infectious Diseases, 66(7). https://doi.org/10.1093/cid/cix1085

Miller, M. A. (2007). Clinical management of Clostridium Difficile-associated disease. Clinical Infectious Diseases, 45(2). https://doi.org/10.1086/519257

Moore, T. (2018, April 26). Probiotics useful in the fight against C. Difficile [Press release]. Retrieved from https://www.shea-online.org/index.php/journal-news/press-room/press-release-archives/588-probiotics-useful-inthe-fight-against-c-difficile

[Online forum post]. (n.d.). Retrieved from https://www.dietitians.ca

Pettigrew, M. M., Johnson, J. K., \& Harris, A. D. (2016). The human microbiota: novel targets for hospital-acquired infections and antibiotic resistance. Annals of Epidemiology, 26(5). https://doi.org/10.1016/j.annepidem.2016.02.007 
Shannon-Lowe, J., Matheson, N. J., Cooke, F. J., \& Aliyu, S. H. (2010). Prevention and medical management of Clostridium difficile infection. British Medical Journal, 340(7747). https://doi.org/0.1136/bmj.c1296

Shen, N. T., Maw, A., Tmanova, L. L., Pino, A., Ancy, K., Crawford, C. V., . . Evan, A. T. (2017). timely use of probiotics in hospitalized adults prevents Clostridium difficile Infection: A systematic review with meta-regression analysis. Gastroenterology, 152. http://doi.org/10.1053/j.gastro.2017.02.003

Sniffen, J. C., McFarland, L. V., Evans, C. T., \& Goldstein, E. J. C. (2018). Choosing an appropriate probiotic product for your patient: An evidence-based practical guide. PLOS ONE. https://doi.org/10.1371/journal.pone.0209205

Starr, J. (2005). Clostridium difficile associated diarrhoea: Diagnosis and treatment. British Medical Journal, 331(7515), 498-501. Retrieved from https://www.jstor.org/stable/25460515

Szajewska, H. (2010). Advances and limitations of evidence-based medicine - impact for probiotics. Annals of Nutrition and Metabolism, 57, 6-9. https://doi.org/10.1159/000309015

Verna, E. C., \& Lucak, S. (2010). Use of probiotics in gastrointestinal disorders: What to recommend? Therapeutic Advances in Gastroenterology, 3(5), 307-319. https://doi.org/10.1177/1756283X10373814

Wilkins, T., \& Sequoia, J. (2017). Probiotics for Gastrointestinal Conditions: A Summary of the Evidence. American Family Physician, 96(3), 170-178. Retrieved from https://www.aafp.org/afp/2017/0801/p170.html

World Health Organization. (2014). Health care associated infections FACT SHEET. Retrieved from https://www.who.int/gpsc/country_work/gpsc_ccisc_fact_sheet_en.pdf Zuccotti, G. V., \& Meneghin, F. (2014). The role of probiotics in nosocomial infections. Italian Journal of Pediatrics, 40. https://doi.org/10.1186/1824-7288-40-S2-A16 